\title{
1. Introduction to the Research Handbook of Sustainability Agency
}

\author{
Satu Teerikangas, Katariina Koistinen, Tiina Onkila and \\ Marileena Mäkelä
}

\section{WHY DOES SUSTAINABILITY AGENCY MATTER?}

There is increasing evidence that the world is heading toward an environmental crisis. Human perturbations have destabilized Earth-system processes at planetary scale (Rockström et al., 2009; IPCC, 2014; Steffen et al., 2015; United Nations, 2019; WWF, 2020). The growing population adds demand for natural resources globally: by 2050, water and food demand are to increase by over $40 \%$ (FAO, 2017; IWMI, 2018), by 2040, global energy consumption is expected to increase by $80 \%$ (IEA, 2018). In other words, the global system appears locked into a trajectory of overconsumption of natural resources coupled with increasing emissions. A consumption and growth-oriented lifestyle seems to have brought humankind to unwittingly destroy the livability of the ecosystems on which its survival depends. The question is: is there a future?

In order for there to be a future-proof future for humanity, there is need for societies across the globe to undertake systemic change toward sustainable ways of living, working, and doing business (Folke et al., 2011; Dyllick \& Muff, 2015; Loorbach et al., 2017). Notwithstanding, the past 30 years have witnessed a shift from an initial marginal interest toward a recent surge of academic and practitioner interest in appreciating the change dynamics required for societies, the private, public, and non-profit sectors to transition toward greater degrees of sustainability (Markard et al., 2012; Köhler et al., 2019). These decades have been plagued by a duality between emerging government- and business-led action, operating first against, and increasingly together with minority green-labeled movements. The focus has been on a top-down approach toward systemic change, with emphasis placed on major institutional and business players and the way in which they manage their stakeholders (Pesch, 2015; Raineri \& Paillé, 2016; Kim et al., 2017).

The Paris 2015 climate negotiations marked a turning point. Decades of incremental or non-action toward sustainable futures had placed humanity on an unsafe path (IPCC, 2014). Based on scientific evidence, global political leaders concurred that, unless urgent and continuous action is undertaken, the future of humanity is at stake.

Since 2015, individuals, in larger numbers, have awoken to this sense of future urgency. Notwithstanding, the past years have witnessed an increasing number of actors initiating action. This includes individuals via, for example, vegan consumption as well as local to global communities, collectives, and social movements, such as 350.org. Corporate players and public organizations in most countries are bound to the Paris 2015 Climate Agreement set to drastically reduce national carbon emissions by 2030/2050. If sustainability transitions (Markard et al., 2012; Köhler et al., 2019) are to succeed, the role of actors, i.e. agency, is critical (Geels, 2002; Koistinen et al., 2020). Put bluntly, the question of sustainability agency 


\section{Research handbook of sustainability agency}

can arguably be considered one, if not the, burning question of our times. This leads one to ask - what is known on sustainability agency based on existing academic literature? In other words, how has prior academic literature studied how individuals and organizations drive a sustainable future?

Taking a closer look at academic knowledge, one finds more questions than answers. Indeed, despite the ongoing and increasing developments in the actor-based practice of sustainability, and increasing research, there is no one body of literature termed 'sustainability agency':

- Based on reviews of the disciplines of management, corporate social responsibility (CSR), and sustainability science in the years 1992-2019, we observed the study of sustainability agency to be scattered both within and across disciplines, with little efforts at cross-fertilization and integration across these bodies of knowledge (Teerikangas et al., 2018; Onkila et al., 2019; Koistinen et al., 2020). In the sustainability transitions literature, recent reviews posit that interest in the study of agency is emerging (Fischer \& Newig, 2016; Koistinen et al., 2018), yet this body of work remains diffuse amid a plethora of terms (Avelino \& Wittmayer, 2016; de Haan \& Rotmans, 2018). Similarly, in management literature, the connection between agency and sustainability has recently been acknowledged (Garud \& Gehman, 2012; Clayton et al., 2015).

- Indeed, the terminology used to appreciate sustainability agency is multifaceted, and spans levels of analysis, as extant theorizing has identified numerous forms of sustainability agency. Management theorists study firms' non-market strategies (Doh et al., 2012), social entrepreneurship (Pacheco et al., 2010), shareholder activism (Goranova \& Ryan, 2014), and employee volunteering (Rodell et al., 2016). Together with sociologists, there is an interest in social movements (de Bakker et al., 2013; Heaney \& Rojas, 2014) and institutional entrepreneurship (Pacheco et al., 2010). This parallels the psychologists' interest in environmental activists (Gousse-Lessard et al., 2013). Environmental management scholars study firms' engagement in external collaborative partnerships (Wassmer et al., 2014) and within-firm sustainability change processes (Haugh \& Talwar, 2010). In sustainability science, the role of niche (i.e. regime-shaping) and incumbent actors is recognized. Numerous terms are thus used to denote sustainability actors (Onkila \& Sarna, 2017; Koistinen et al., 2018; Teerikangas et al., 2018). While agency is studied, an integrative view of actor types, roles, and their means of influencing sustainability transitions appears to be amiss (Geels \& Schot, 2007; Garud \& Gehman, 2012; Markard et al., 2012; Pesch, 2015).

- What is more, extant theorizing has focused on institutional-level analyses, with less appreciation of the organizations involved in sustainability transitions (Markard et al., 2012). More research on micro-institutional actors (Farla et al., 2012), including firms, cities, and third sector organizations is called for (Lambell et al., 2008).

- Finally, extant theorizing has often assumed a static categorization of agency in sustainability transitions, using terms such as 'niche' (i.e. proactive, change-driving) vs. 'incumbent' (i.e. resistant, regime) agency, thus implying that some actors are more active than others (Williams \& Millington, 2004; Geels, 2011; Markman \& Waldron, 2014). All the while, institutional entrepreneurs (Lawrence et al., 2009; Pacheco et al., 2010) shape (niche and/ or incumbent) organizations from within. More research is warranted on such forms of 'embedded agency', where individuals operate as change agents within organizations (Seo 
$\&$ Creed, 2002). We further lack comparative overviews of how professionals across the organizational hierarchy operate as embedded agents (Crilly et al., 2008; Teerikangas et al., 2018).

Summing up, there is no one book, article, author, or discipline to turn to on sustainability agency. Such a scattered state of affairs amid academic research might explain the challenge that individuals and organizations have in assessing their role vis-à-vis sustainable futures. In recent years, the question of 'what ought I do?', or 'do my actions matter?' have been increasingly raised. This leads to ask - what is sustainability agency, actually? In this research handbook, we take up the challenge of exploring and making sense of what sustainability agency is, as it has been studied across disciplines. The scientific and societal gap addressed by this research handbook is in appreciating what sustainability agency is.

To this end, the main contribution of the handbook is in developing an integrative, interdisciplinary perspective to sustainability agency. In so doing, the aim is to solidify an agentic perspective to the interdisciplinary field of sustainability studies. Acknowledging the theoretical and disciplinary diversity in the study of sustainability agency, this handbook builds on related, hitherto largely disparate disciplines, where phenomena related to sustainability agency have been studied. Such disciplines include, but are not limited to, sustainability science, environmental psychology, law, geography, public policy, CSR, strategic management, management and organization studies, industrial and consumer marketing, accounting, project management, as well as construction management.

This introductory chapter proceeds as follows. Any attempt at appreciating sustainability agency needs to start with an appreciation of the concepts it draws upon - sustainability and agency. Indeed, both concepts are historically loaded with numerous definitions, perspectives, including ontological and epistemological differences. While our purpose is not to provide an exhaustive view of either concept, we proceed next to a selected sample of key authors and sources that we consider as central in making sense of what (a) sustainability, and (b) agency is. The chapter ends with an overview of the aims and contents of the other 26 chapters included in this handbook.

\section{WHAT IS SUSTAINABILITY?}

\section{Origin of the Concept}

The notion of sustainability has been subject to heated debate within academia in recent decades (Hediger, 1999). It is also one of the key concepts in national and international policy discourse (Seefried, 2015). Taking a closer look, though, the origin of the concept dates long back to our history. Already in 1848, John Stuart Mill ([1848] 1999) stressed that indefinite economic growth would eventually wreck the quality of life and the environment. More recently, in the light of waning resources and increased pollution due to a myriad of emissions, Meadows et al. (1972) came to the same conclusion. They argued that continuous economic growth was unsustainable and would result in the deprivation of the natural environment.

In the $1960 \mathrm{~s}$ and $1970 \mathrm{~s}$, the discussion on sustainability started to escalate, when awareness on sustainability challenges faced by humankind started to rise through such incidents as the publication of Rachel Carson's Silent Spring ([1962] 2009), the work of the Club of Rome 


\section{Research handbook of sustainability agency}

(Meadows et al., 1972) and the oil crisis of the 1970s (see Seefried, 2015). To this end, governments since Limits to Growth (Meadows et al., 1972) and the oil shocks of the 1970s have been trying to achieve more sustainable societies (Chappin \& Ligtvoet, 2014).

This has led to, perhaps the most broadly applied, definition of sustainable development by the United Nations World Commission. The definition was introduced in the 1987 United Nations World Commission on Environment and Development (WCED), Brundtland Report Our Common Future, as follows: 'Sustainable development is development that meets the needs of the present without compromising the ability of future generations to meet their own needs' (Brundtland, 1987).

The above presented definition of sustainability (or sustainable development) essentially grasps the understanding of sustainability held at the time. The definition helped people to start to perceive limits to growth and start considering alternative future scenarios, but it has been recently criticized for its vagueness (Seefried, 2015), and therefore alternative ways to define, and especially to concretize, what sustainability is, have been presented.

\section{Three (or Four) Sustainability Dimensions}

In more current discussions, sustainability is often defined as consisting of three dimensions: environmental, social, and economic (Elkington, 1999; Kuhlman \& Farrington, 2010), referring to the wellbeing of the natural environment, human beings as well as support for financial outcomes. More recently it has also been debated that cultural sustainability should be included as the fourth dimension of sustainability (Birkeland, 2008; Soini \& Birkeland, 2014). By cultural sustainability, the preservation of human cultures is referred to, including issues such as heritage, vitality, diversity and eco-cultural civilization (Soini \& Birkeland, 2014). Thus the concept of sustainability is broadly understood as multidimensional. The relationships between these different dimensions are acknowledged as intertwined (Giovannoni \& Fabietti, 2013), when influencing one of those also influences others. Kuhlman and Farrington (2010) attach also potential dangers to this change from moving from the Brundtland Report's definition to a dimensional view of sustainability - they see risks in separating such similar aims as social and economic dimensions as well as a risk in downplaying one dimension at the cost of another.

The focus on strong versus weak sustainability is also strongly debated (Dyllick \& Muff, 2015), and the decision about which definition to follow is fundamental. Weak sustainability is based on the belief of full substitutability of natural capital whereas strong sustainability supports the view that this substitutability is seriously limited due to the importance of natural capital for human existence and wellbeing (Pelenc \& Dedeurwaerdere, 2015). Weak sustainability does not differentiate between the wellbeing provided by the manufactured capital and natural capital (Pelenc \& Dedeurwaerdere, 2015). The proponents of strong sustainability argue for unsubstitutability of natural capital. Instead, it is seen as a complex system of natural elements that provides human society multiplicity of functions and services (De Groot et al., 2003; Brand, 2009). Thus strong sustainability sees limits for the use of natural resources on the current level of economic activity (Málovics et al., 2008). 


\section{The United Nations' Sustainable Development Goals}

At present, sustainability is understood as a multidimensional concept that is affected by various research disciplines (Hediger, 1999). The prior definitions of it are, at the same time, described as vague and responses are seen to contain arbitrariness, and our understanding of what is actually meant by sustainability seems to lack clarity. Especially responses to the question of 'what is sustained' are seen as arbitrary (Christen \& Schmidt, 2012). Therefore, more work has been targeted at concretizing the concept, and instead of focusing on the rather abstract three (or four) dimensions of sustainability, at finding more concrete ways to measure and conceptualize what is actually sustained in sustainability and what are the targets to be promoted and reached in global sustainability change. The discussion is labeled by a focus on strong sustainability. The United Nations' Sustainable Development Goals (SDGs) represent such work on sustainability. They have gained worldwide attention, and the targets are increasingly taken into account by individuals as well as societal and business actors.

The United Nations defined 17 SDGs to empower current societies to contribute to a more sustainable future (United Nations, 2020). These goals address global sustainability challenges, such as poverty, health, education, equality, responsible consumption, and climate action, and they offer concrete targets for each goal. The work on these globally shared goals started at the United Nations Rio+20 summit in Brazil in 2012, and the priorites between the goals have since been debated (Griggs et al., 2013). The work done on the SDGs advances and concretizes the prior focus on three, or four, dimensions of sustainability. Within the goals, sustainability is divided into more detailed categories influencing human, environmental, and economic wellbeing and equality. It is notable that the defined SDGs interact - and thus influence the advancement of each other. The dynamic nature of SDGs may support or hinder the advancement of the other goals (Nilsson et al., 2016). Thus, further work is required, especially locally, on how to treat the potential trade-offs between SDGs and balance between stakeholders' interests.

\section{Sustainability within Organizational Contexts}

Within organizational contexts, the sustainability discussion has been largely covered under the term CSR. The concept refers to the inclusion of sustainability principles within organizations, and has been built on the same dimensions as the concept of sustainability: social, environmental, and economic (Dahlsrud, 2008). However, multiple researchers have criticized the rather inconcrete and unlimited definition, and therefore added perspectives to the discussions: for example stakeholder and voluntariness dimensions (Dahlsrud, 2008) and ethical and sustainability dimensions (Sarkar \& Searcy, 2016). Multiple definitions for CSR have been offered, many of which focus on embracing the three dimensions of sustainability within the organizational context. Furthermore, it has been debated whether we should even speak of CSR or actually of organizational/corporate sustainability, since both terms focus on the triple bottom line approach to sustainability. For example, Aguinis $(2011,855)$ proposed a definition of sustainability as 'context-specific organisational actions and policies that take into account stakeholders' expectations and the triple bottom line of economic, social, and environmental performance'.

Similar vagueness is related to CSR and corporate sustainability concepts as to the concept of sustainability (Sarkar \& Searcy, 2016) and both the terms lack conceptual clarity 
(Knippenberg \& de Jong, 2010; Bice, 2017). It is especially questioned how these concepts enable businesses to become truly sustainable and how business can make effective contributions to sustainability challenges (Dyllick \& Muff, 2015). True sustainablity in organizations means contributing to strong sustainability, requiring profound changes, for example, in business logics and models, organizations' core activities, and modes of organizing. In their discussion of how companies can contribute to strong sustainability, Málovics et al. (2008) argue that influencing consumption patterns is required in addition to changes in corporate behavior.

In this book, we are interested in how agency relates sustainability. We acknowledge the vagueness of the term sustainability, and the need for further debate on what sustainability actually means in different contexts and what it is that is to be sustained. However, we wish to contribute to understanding of importance of agency for different types of sustainability challenges, with a particular focus on environmental sustainability. This means that, instead of exploring the multiple meanings of the sustainability concept, we aim at increasing understanding of the role of different actors in sustainability change. We now move on to explaining the concept of 'agency' and exploring its different meanings.

\section{WHAT IS AGENCY?}

The question and study of agency cuts across the history of the humanities and social sciences, with roots in early philosophical inquiry. While of interest, a thorough, cross-disciplinary perspective on agency and its historical development is beyond the scope of the present research handbook. For the purposes of this handbook, we have been selective in our approach to agency.

We start our query of 'what is agency' via an etymological and historical perspective, assessing how the concept of agency is introduced in the Oxford English Dictionary (OED, n.d.). Thereafter, we proceed with our query by focusing on three disciplines - sociology, social cognitive psychology, and management studies. These three disciplines have given explicit theoretical and empirical attention to the study and concept of agency. They are also used by this handbook's authors in their definitions of agency. It deserves mentioning that, in this section, our focus is on theories of agency, not sustainability agency. While the former is the focus of this section, the latter is the focus of this handbook.

Moreover, these disciplines relate to and bear an impact as regards the study of sustainable futures. For one, the plethora of background theories underlying the sustainability transitions literature bear sociological underpinnings (Avelino, 2017). All the while, this literature is critiqued for not sufficiently incorporating psychological theories (Bögel \& Upham, 2018). For another, if organizations' and businesses' action is to be shaped toward greater degrees of sustainability, then an appreciation of how this discipline views agency is critical. Finally, psychological theories, in their many forms, each provide different perspectives to individual agency (see Chapter 2). In this chapter, our focus is on social cognitive psychology given its explicit focus on agency.

\section{Starting with the Dictionary Definitions}

The Oxford English Dictionary defines agency two-fold. A first definition of agency provides an instrumental and operational definition of agency for everyday use. It regards agency as 
a person or organization acting on behalf of another, or providing a particular service. In this regard, agency is viewed as the process of acting as an agent, i.e. the position, role, or function of an agent, deputy, or representative. In its earliest use in the mid-seventeenth century, agency referred to ambassadorship or embassy. Since 1760 in Biographia Britannica (1766), agency has referred to a business, body, or organization providing a particular service, or negotiating transactions on behalf of a person or group. When used with capital initials, it can refer to the names of such businesses or organizations, as in e.g. Chief Intelligence Agency (CIA) in the United States.

However, it is the second definition of agency that, though neatly defined in the Oxford English Dictionary, has come to characterize many a heated debate across the social sciences throughout the centuries. This second definition, in its broadest sense, considers agency as action, as the capacity to act. On the one hand, this can refer to the ability or capacity to act or exert power, active working or operation, an action or activity. Early mentions of such agency can be found in seventeenth- to nineteenth-century writings regarding the state, inquiries on the freedom of will, philosophical essays, family essays, or in political inquiry.

On the other hand, agency can alternatively refer to action or intervention producing a particular effect, thus referring to a means, instrumentality, or mediation. An early mention is in the historical accounts of Queen Elizabeth II's era and in writings on the difference between the Church and the Court of Rome. Other early mentions relate to medicine as in physical agency, religion as in angels' agency, politics, geology as in geologists excluding the agency of fire from the formation of rocks (Bakewell, 1815), or geography, where Ackroyd (2009, 203) recently asked whether Venice 'exists and survives by the agency of some inner or intrinsic force'. Mentions can also be found in biology as in the agency of animals. It is thus that Darwin (1859), in The Origins of Species, refers to the agency of certain insects in transferring pollen from one flower to another, or the Scientific American Monthly (1921) referring to the agency of fleas in carrying the bubonic plague from sick rats to man.

Summing up, the notion of agency occurs in Western political, scientific and religious writings from the seventeenth century onward. These considerations view agency in living matter, be it humans, animals, fire, or in the collective, institutionalized action of people via organizations such as embassies, societal Agencies, or cities. It deserves to be mentioned that given the action-orientation in the latter definition of agency, it has also been used to categorize seemingly non-living beings in religious writings, as in the example of angels' agency.

\section{Agency as Viewed by Sociology}

Agency is a central concept in sociological thinking (Giddens \& Sutton, 2017). Given that all sociological theorizing has, in some form or another, taken a stance toward agency, it has been argued that a history of sociological theory from the perspective of agency could be written (Dawe, 1978). While classical sociological theories in the structuralist tradition give primacy to structure over agency, symbolic interactionist theories emphasize agency (for an overview, see e.g. Giddens, 1984; Emirbayer \& Mische, 1998).

In the recent decades, a quest to find integration between these two extremes has come to characterize contemporary sociological theorizing. Two approaches can be identified (Ritzer, 2000). On the one hand, American sociologists have sought integration between micro and macro perspectives to sociology. Perspectives to agency via micro and macro integration can be found in the work of Norbert Elias, George Ritzer, Randall Collins, Jeffrey Alexander, 
James Coleman, and Norbert Wiley. On the other hand, their European counterparts have heatedly discussed the relationship between structure and agency, to the extent that this debate has been described as the issue in modern social theory (Archer, 1988). Indeed, Archer (1988) argues that the linkage between agency and structure has become the 'acid test' of a general social theory and the 'central problem' in theory. Key theorists in this school include Anthony Giddens, Margaret Archer, Pierre Bourdieu, and Jürgen Habermas.

Acknowledging this diversity in theorizing on agency, in the following, we proceed to a selected view of five perspectives to agency in contemporary sociological thinking. The first three perspectives rest on original theorizing, as regards agency vs. structure (Giddens, 1984; Stones, 2005), agency vs. culture (Archer, 1988), and actor-network theory (ANT; Latour, 1987). The latter two perspectives offer review-based findings on agency, as in Dietz and Burns's (1992) agency typology, and Emirbayer and Mische's (1998) temporal perspective to agency. In this review, we thus bring forth the theoretical work and review-based work of four contemporary sociologists respectively.

\section{Agency vs. structure}

A contemporary author on theorizing on the relationship between agency and structure is Giddens, who draws on prior sociological theorizing in his work (Craib, 1992). He argues that one cannot focus on either structure or agency as polar opposites in theorizing. Instead, via the notion of 'recurrent social practices', he develops his theory of structuration on the relationship between agency and structure (Giddens, 1984). In Giddens's view, agency and structure are in a dialectical interplay (Bernstein, 1989), or two sides of the same coin (Ritzer, 2000) given that all social action involves structure and vice versa. Thus, agency and structure are part and parcel of human activity. Giddens sees practices as recursive, in that they are continuously created and recreated by actors, in so doing recreating structure. In expressing themselves as actors, people are engaging in practice. This leads Bernstein (1989) to argue that agency is reflexively and recursively implicated in social structures. Giddens distinguishes between discursive consciousness, i.e. one's ability to describe one's actions in words, and practical consciousness, i.e. the actions that one takes for granted without being able to express in words this doing. It is thus that Giddens places primacy for doing over speaking.

Giddens places much emphasis on agency (Baber, 1991): 'agency concerns events of which an individual is a perpetrator ... the individual could, at any phase in a given sequence of conduct, have acted differently. Whatever happened would not have happened if that individual had not intervened', and 'agency refers not to the intentions people have in doing things but to their capability of doing those things in the first place' (Giddens, 1984, 9). However, Giddens's agency is not necessarily intentional, given the unintended consequences also of intentional action (Merton, 1949).

Notwithstanding, Giddens affords agents much power (Ritzer, 2000). In this view, agents have the ability to make a difference in the social world, influencing the causal powers of others; alternatively taken, an actor ceases to be an agent if he/she loses the capacity to make a difference, i.e. exercise some sort of power $(1984,14)$. Thus Giddens accords power to the actor and action, contrasting views focused on the actor's intent, as in phenomenology, or the external structure, as in structural functionalism.

Structure refers to the 'structuring properties that ... make it possible for similar social practices to exist across varying spans of time and space' (Giddens, 1984, 17). Thus structures do not exist; instead, social phenomena can become structured. Giddens considers that structure 
only exists in and through the activities of human agents (Giddens, 1989, 256). This contrasts with structuralist theories that offer a coercive, external view to structure. While classic sociologists have often studied the constraining effect of structure, Giddens sees structure as both enabling and constraining. Giddens defines social systems as reproduced social practices (1984, 17, 25). Thus, social systems do not have structures, yet they do exhibit structural properties. Thus, structures become manifested in social systems in the form of reproduced practices (Ritzer, 2000, 525). Based on these concepts, Giddens defines the structuration of social systems as 'the modes in which such systems ... are produced and reproduced in interaction' $(1984,25)$. Central to this theorizing is the duality of agents and structures. Thus, 'the structural properties of social systems are both medium and outcome of the practices they recursively organize'.

In response to the criticism attracted by structuration theory regarding its neglect toward the internal worlds of actors, Stones (2005) developed Giddens's work into what is now referred as the 'strong structuration' framework. Whereas Giddens was especially interested in relatively abstract ontology, Stones went further and encouraged researchers to explore empirical case studies involving specific actors and structures where individual agents are situated in a web of position-practice relations (Coad et al., 2015). While the duality of structure, i.e. the inseparability and thus duality of agency and structure, remains a defining construct in strong structuration theory, Stones states that duality is best understood through the analysis of a quadripartite framework of interrelated components that spans external structures, internal structures, active agency, and outcomes (Coad et al., 2015). In this framework, external structures obligate the actions of actors; internal psychological structures are found within actors; active, intentional agency is assumed; and outcomes occur that are internal and/or external to the actor (Stones, 2005; Schwandt \& Szabla, 2013; Aldous, 2014; Fjellstedt, 2015; Upham et al., 2018).

Stones (2005) describes the four elements of strong structuration as follows: external structures are separate from the actor and they set boundary conditions. The external structures define the culturally and socially embedded conditions, practices, and resources that influence and inform the actions and practices of actors (Aldous, 2014). External structures include, for example, laws and regulations. Internal structures emphasize the phenomenological conditions of an actor's interaction with external structures (Aldous, 2014). Internal structures include two categories: first, those that are general-dispositional, such as norms, values, and attitudes in relation to one's analytic frame; and, second, those that are conjuncturally specific, regarding actors' knowledge and understanding of their immediate and broader context. Upham et al. (2018) have noted that, while these two categories are fundamentally distinct, in practice there might be some overlap. Last, within this framework, active agency relates to processes of deliberate, sometimes strategic action (Garud \& Karnøe, 2001).

\section{Agency vs. culture}

Margaret Archer has focused on connecting agency and culture (Archer, 1988). Critiquing Giddens's structuration theory, she introduces an alternative perspective based on systems theory (Archer, 1982). Central to her theorizing is the notion of morphogenesis, which implies that complex changes lead not only to changes in the structure of the system but also to an end product, structural elaboration. In this view, there are emergent properties in change that can be separated from the actions and interactions that produced them (Ritzer, 2000). The mor- 
phogenetic perspective views change processes over time, as endless sequences of structural change.

Archer's main critique has been directed toward Giddens's notion of duality. In contrast, Archer views structure (and culture) and agency as analytically distinct, yet intertwined in social life. This enables studying their interplay over time, and it is this interplay that is at the core of her interest. Archer further critiques the fact that Giddens's structuration cycles go on and on, without any direction. In Archer's morphogenetic approach, change evolves toward structural elaboration.

While the bulk of sociological theory has focused on structure, Archer's focus is on culture, the realm of non-material phenomena and ideas. She sees a conceptual distinction between culture and structure, considering them as autonomous, though in practice intertwined in the real world. In so doing, Archer thus promotes cultural sociology (Lamont \& Wuthnow, 1990).

\section{Actor-network theory}

While the sociological discussion considering agency typically embraces human agency, ANT adds to the debate by broadening the notion on agency beyond human actors. ANT originated from sociology and the science and technology studies (Law, 1992); it emphasizes structure forming from a range of things, heterogeneity, and messiness of technological development in local practices, in which social and technical elements interrelate and constitute each other from the beginning (Geels \& Schot, 2007). The vested notion in ANT is that knowledge, which covers aspects such as knowledge of agents, social institutions, machines, and companies, may be perceived as a product or outcome of a network of heterogeneous materials (Law, 1992). To this end, ANT is an approach that analyzes the building of actor-networks (Latour, 1987). This idea builds on the notion that there are no actors without networks.

What distinguishes ANT from other theories is its view on agency. While typical studies considering sociology and social networks emphasize the social relations of individual human actors and their frequency, distribution, homogeneity, and proximity, ANT does not limit itself to human individual actors but extends the word actor to include non-human, non-individual entities (Latour, 1996). The non-human or non-individual entities may have a similar impact on their environment as that of human actors. This implies that non-human and non-individual entities affect human actors. Thus, the influence of a non-human environment should not be overlooked in the study of agency.

The aim of ANT is to explore the essence of societies and nature by employing social networks to rebuild social theory (Latour, 1996, 2005). Zooming closer, ANT is based on the assumption that social and technical developments are mutually embedded, which means that it is not possible to explore the social without simultaneously studying relational materiality (Law, 2008). However, it is important to emphasize that this theory does not exclude human agency. In actor-network webs, the distinction between human and non-human is of little initial analytical importance: people are understood as relational outcomes that include both the human and the non-human, while object-webs conversely include people (Law, 2008). This leads to certain networks being labeled either as 'human' or 'non-human', but this is of secondary concern, as the emphasis is on the actor-networks (Law, 2008).

\section{Typology of agency}

When can agency be attributed to a social actor? Integrating earlier work in sociology, Dietz and Burns (1992) claim that four criteria need to be met in order for agency to be attributed to 
a social actor. First, the actor must be able to make a difference, i.e. have power. Second, the actor's actions are intentional. Third, the actor must have choice in one's action. Fourth, agents are reflexive, as they monitor their action in light of forthcoming action. This leads the authors to argue that agency is best viewed as a continuum - all actors have some degree of agency, yet no actor has full, unrestrained agency.

Based on their review of prior theorizing on agency, the authors further posit three structural constraints on agency. For one, imagined actions might not be possible in the technological and physical circumstances within which one operates. For another, structure makes certain actions necessary, while making others quasi-impossible. Third, agency is influenced, enabled, and constrained by other agents. In a similar vein, in 1993, Cochran and Laub, in their book Becoming an Agent see an agent as a model that is capable of inspiring a person, providing strong motivation to strive for more agency.

Third, the concept of agency operates at different levels of analysis, thus escaping the notions of being purely a micro-level or macro-level phenomenon. Burns and Flam (1986) offer a comprehensive perspective to human agency. They consider that human agents can refer to individuals, organized groups, organizations, and nations. It deserves mention that, in a similar vein, the concept of structure, which is often theorized in tandem with agency (Bandura, 2006; Aylett, 2015), can refer to either large-scale social structures or the micro-structures as in interpersonal interaction (Ritzer, 2000).

\section{Temporal perspective to agency}

Via their extensive and thorough review of extant theorizing on agency from Greek philosophy through to contemporary sociology, Emirbayer and Mische (1998) offer a temporal perspective to agency bridging past, present, and future. Put shortly, they consider agency as a 'temporally embedded process of social engagement' informed by the past, projecting onto the future, while acting in the present. They define agency as 'the temporally constructed engagement by actors of different structural environments - the temporal-relational contexts of action - which, through the interplay of habit, imagination and judgment, both reproduce and transform those structures in interactive response to the problems posed by changing historical situations' (p. 970). It is thus that past experiences form the habitual dimension of agency, while humans' projective capacity enables considering alternative future paths. The present refers to an individual's practical-evaluative capacity to make sense of the past compared against future desires given the present circumstances. The authors argue that all three temporal dimensions, while analytically distinguishable, operate in a continuous interplay at any given moment.

The authors thus conceptualize agency via three constitutive, temporally embedded, elements: iteration (past orientation), projectivity (future orientation), and practical evaluation (present orientation). Taking a closer look, the internal structure of iteration consists in selective attention, recognition of types, categorical location, maneuver among repertoires, and expectation maintenance. The internal structure of projectivity consists in anticipatory identification, narrative construction, symbolic recomposition, hypothetical resolution, and experimental enactment. Finally, the internal structure of practical evaluation consists in problematization, characterization, deliberation, decision, and execution.

In their extensive review of prior theorizing on agency, the authors critically observe that the bulk of prior philosophical and sociological theory has focused on the past-dimension of agency. In contrast, interest toward the future dimension of agency has been recently ignored, 
though previous interest across the social sciences can be identified. Most surprisingly, the present dimension of agency has remained largely undertheorized in sociology, while its roots range from Aristotelian ethics to theories of critical deliberation and feminist theories.

\section{Agency as Viewed by Social Cognitive Psychology}

In the field of psychology, we draw in particular from the definition of Albert Bandura, who, in his paper 'Toward a Psychology of Human Agency' (2006) offers an agency-based theory of human development, adaptation, and change. This seminal paper sets the basis of social cognitive theory, which rejects the duality between human agency and social structure. Instead, it considers that humans and their surrounding social structure coevolve, both bearing on one another. To this end, Bandura argues that it is the emergence of advanced symbolizing capacity that enabled humans to shift from being subservient toward their immediate environment toward shaping it, as well as altering their life circumstances and life courses. While all psychological theories to some extent treat explicitly or implicitly with agency (see Upham et al., Chapter 2 of this volume), the field of psychology has been critiqued for a traditionally passive stance toward agency (Bandura, 2001). While the field has advanced in terms of the inner workings of the mind (increasingly likened to a computer), as well as an appreciation of human functioning within one's social environment, the connection between active agency and the environment has often been left unattended to.

In contrast, social cognitive theory (Bandura, 2001, 2006) acknowledges the active actor acting and shaping the social structures one finds oneself in. In so doing, this field of psychology seeks to appreciate human development, adaptation, and change. Bandura considers that to be an agent is 'to intentionally make things happen by one's actions' $(2001,2)$, or 'to influence intentionally one's functioning and life circumstances' $(2006,164)$. Bandura defines human agency via the properties of intentionality, forethought, self-reactiveness (i.e. the capability to execute), and self-reflectiveness. These properties define in the author's view 'what it means to be human' $(2001,6)$. Put differently, the capacity to exercise control over the nature and quality of one's life is the essence of humanness (Bandura, 2001).

As part of self-reflectiveness, efficacy beliefs are a central element, if not the foundation of personal agency. Efficacy beliefs reflect people's beliefs in their capability to exercise some measure of control over their own functioning and over environmental events (Bandura, 1997). Put shortly, efficacy beliefs are rooted in the belief that one has the power to produce effects by one's actions. This argument has received empirical support via studies and meta-analyses (Holden, 1991; Holden et al., 1990). Efficacy beliefs bear an impact on whether individuals engage in self-enhancing or self-hindering thoughts, and have an influence on the types of activities and environments individuals engage with within their life course.

Social cognitive theory differentiates between three types of agency, recognizing that daily activity requires their mutual interplay. These three modes of agency include personal agency, exercised individually, whereby individuals shape their own lives and their surroundings. Proxy, or socially mediated agency, refers to situations wherein individuals do not have direct control over the conditions that affect their lives. In an effort to exercise their agency, individuals then operate by influencing others who have the resources, capacities or knowledge. Given that individuals do not lead fully autonomous lives, in many instances, they engage in collective agency, whereby jointly with others, they pool the necessary resources to shape their 
future. Bandura (2006) observes that collective belief in a group's collective capability to alter situations is a key element of collective agency.

Acknowledging the detrimental effect of human agency on the natural environment and the looming potential of unsustainable futures, Bandura (2006) asks the question of how human agency can be better put to use to shape better and sustainable future trajectories. He thus does not sign up to a passive perspective of agency, instead arguing for the necessity to recognize the potential, and the responsibility vested in human agency.

\section{Agency as Viewed by Management}

Agency has been a central, much discussed concept in management. Upon closer look, one can discern between theorizing on agency on the one hand, and agency theory on the other.

Starting with the former category, the perspective to agency in management theory, has undergone alterations, transformations and heated debate. In his conceptual paper, Caldwell (2005) provides an overview of how discourses on agency and change have evolved since the inception of management theories in the 1960 s to the early 2000 s, identifying four discourses. His argument is that perceptions of agency and change have coevolved. The earliest discourse was a rationalist one, building on a rational view of agency, paralleling theorizing across the social sciences, from economy to psychology. The rationalist view builds on Kurt Lewin's work, and has since come to characterize the organizational development school of change management. In this tradition, agency is considered as rational and expert-based, autonomy is associated with group rather than individual learning, and the change agent offers reflexivity via feedback. Another early discourse is the contextualist discourse, which builds on Simon's (1947), Quinn's (1980), Mintzberg’s (1994) and Pettigrew's (1997) work. Caldwell (2005) summarizes the main tenets of this discourse as the iterative, non-linear nature of change, the multiplicity of levels of analysis, the influence of micro-politics and conflicts, and the unintended consequences of rational action. The third discourse is labeled the dispersalist discourse, as it provides a decentered perspective to the agency-change debate. This discourse has paralleled the rise of virtual workplaces in recent decades. Theoretically, this discourse resonates with theorizing on the learning organization (Senge, 1990), communities of practice, distributed leadership, and complexity theories. The fourth and most recent discourse is constructionist. In this perspective, the notion of agency disappears. The main tenets of this discourse are anti-rationalism, anti-scientism, anti-essentialism, anti-realism, a critique of dualistic views, a questioning over the boundaries of organizations, and reflection on the role of power. In this discourse, agency and change are enacted in the present.

Moving on, paralleling these debates the so-called 'agency theory' has become a classic in management theory (Eisenhardt, 1989). Agency theory also has its roots in the 1960s economists' work on risk sharing between individuals or groups (e.g. Wilson, 1968). Building on this work, agency theory was developed to appreciate the agency problem, i.e. what happens when cooperating parties have different goals and division of labor (Jensen \& Meckling, 1976). Agency theory is focused on situations where one party (i.e. the principal) delegates work to another (the agent), where their relationship is described via the metaphor of a contract. It seeks to solve the problematic situations of conflicting goals between principal and agent, the difficulty for the principal to verify the agent's doing, and differing attitudes toward risk. It deserves mention that the unit of analysis in agency theory is the contract between the principal and the agent, and thus the theory seeks to develop the most efficient 
form of principal-agent contracting. A key question therein relates to whether a behavior- or outcome-oriented contract is most efficient. Agency theory views people as self-interested, boundedly rational, and risk averse. Theorists in this field seek to develop a general theory of the principal-agent relationship, applicable to any principal-agent dyad such as employeremployee and buyer-supplier. It deserves mention that management theories and their role vis-à-vis the (un)sustainable practices taught in business schools has been subject to critique, particularly as regards their negative assumptions on human nature (Ghoshal, 2005).

\section{Concluding Thoughts on Agency}

In the previous sections, we proceeded to an overview of how selected authors in three disciplines approach and view agency. Based on this understanding, this section concludes with what is known on agency in extant theorizing in sociology, social cognitive psychology, and management, and how this matters from the perspective of this handbook.

The perspectives covered in the previous sections provide different lenses to agency. These lenses exist within and across disciplines. Starting with sociology, while some discuss the relationship between structure and agency and the resulting structuration processes (Giddens, 1984; Stones, 2005), others consider culture and agency and the resulting systemic change processes (Archer, 1988). Still others offer a temporal perspective, considering agency as occurring in ongoing negotiations between past, present, and future (Emirbayer \& Mische, 1998). A further perspective is to see agency taking place in social networks (Latour, 1987; Law, 1992). While theories in psychology have avoided offering active takes on agency, the recent social cognitive perspective aligns with the agency-structure debates in sociology, where agency is viewed from an active lens taking place within social structures (Bandura, 2001, 2006). Finally, a closer look at management theory identifies four discourses on agency and change since the 1960s (Caldwell, 2005), this coexisting with agency theory that views actors as self-interested and boundedly rational (Eisenhardt, 1989).

It is thus that our overview of differing perspectives on agency illustrates how the debate on agency is raging. This debate has taken different forms across time, within and across scientific disciplines. Put differently, the question of agency has been answered in several ways, throughout the centuries, across the sciences, as academics have taken changing stances toward the subject matter. Thus, one needs to tread the field of agency with care, acknowledging the theoretical grounding upon which one operates, the underlying assumptions per theory and paradigm, each theory's epistemological and ontological positioning, and historical underpinning (Emirbayer \& Mische, 1998; Ritzer, 2000).

The relationship between agency and structure deserves particular attention. Indeed, authors' and research traditions' positioning of agency toward structure marks a classic divide within the social sciences. Authors' views of structure differ, as do authors' views on agency. While some theories directly address the agency-structure relationship in their theorizing on agency (e.g. Giddens, 1984; Stones, 2005), others are geared to providing primacy toward agency - as in phenomenology - or to structure - as in structuralist or institutional theories. Looked at from this perspective, stances toward agency across the social sciences can be analyzed as pendulum or paradigm shifts (e.g. Emirbayer \& Mische, 1998; Caldwell, 2005). Taking a step further, it can even be argued that the notion of agency is implicitly welded in all theories of social sciences, whether explicitly stated or not. This leads to the question of how past, prevailing and emerging scientific paradigms attend to questions of agency. Summing 
up, given the variety of perspectives on agency prevailing in sociology, psychology, and management, researchers in the study of sustainability agency need to tread this field with care. If agency as a concept is hard to grasp, how can it be connected to sustainability, let alone sustainability agency? Let us attempt to simplify matters next.

To begin with, agency appears in many forms. Theorizing on agency across the social sciences implicitly equates agency with living beings, in particular human agency (Ritzer, 2000), or in biology the agency of animals (Darwin, 1859). Alternatively, non-human, non-individual agency is studied (Latour, 1987; Law, 1992). Further, material agency exists (Knappett \& Malafouris, 2008). In its earlier forms, it was studied, for example, in geology as regards the agency of fire vs. rocks (Bakewell, 1815).

Agency can further operate at different levels of analysis. The bulk of theorizing in the social sciences has equated human agency with individual-level agency (e.g. Emirbayer \& Mische, 1998; Bandura, 2001). However, agency can also refer to collectivities that act (Crozier \& Friedberg, 1980; Ritzer, 2000), such as social classes (Touraine, 1977), or even cities (Ackroyd, 2009). What is more, agency can materialize in relationships with others. In other words, agency can also operate at the interpersonal level as proxy agency (Bandura, 2001), or relational agency (Aylett, 2015; Burkitt, 2015).

It deserves mention that there is disagreement within and across the disciplines as to the nature of the agent. Furthermore, the varying theorists offer different characteristics to agency. For one, the bulk of theories focused on agency provide an active take on agency, where agency relates to the capability to act and make a difference (Giddens, 1984), and is considered as intentional and reflexive (Dietz \& Burns, 1992; Bandura, 2001). All the while, a markedly different perspective is provided by 'agency theory', influential in economics, legal studies, and management, which can critically speaking be considered as seeking to limit the active powers of actors and to ensure their alignment, per contract, with the principal, be it a manager, owner, or buyer. This theory bears a more negatively attuned view of agency as self-interested, boundedly rational and risk averse. In agency theory, agents that are too active might act in misalignment with the principal's and the contract's interest. In this handbook, our perspective on agency aligns with the former, i.e. positively active, perspective on agency.

In this handbook, we build upon definitions of agency that view agency as an individual's or collective's capacity to act (Oxford English Dictionary, n.d.; Giddens, 1984; Dietz \& Burns, 1992). While acknowledging other forms of agency, our foremost focus is on human agency. Compared to animals or material, humans have the ability to reflect on what it means to act and undertake agency. The focus on one's 'capacity to act' explains why questions of agency can be considered to define what it means to be human (Bandura, 2001), and why questions of agency, whether framed via the concept of agency explicitly or not, can be considered to characterize the history and evolution of humankind as well as the rise and fall of civilizations. The question of an individual's, collective's, or collective of collectives' capacity to act is central to appreciating how humankind can steer their actions, life, and the personal or societal circumstances they find themselves in. One's capacity to act burrows into what it means to be alive, how and how much one acts toward (which) given purpose. Put differently, it reflects on the classic, and ongoing problem of free will and determinism (Emirbayer \& Mische, 1998).

In view to closing, while much progress in the study of agency has been made, many a question remains unanswered. To begin with, in view of enhancing sustainability agency, the question of one's capacity to act gains primacy. What are the means by which individuals' and collectives' capacity to act can be enhanced for sustainable futures to materialize? Current 
research in sociology is biased toward a past-focused perspective on agency, in so doing largely ignoring agency as the enactment in the present, geared toward a future state (Emirbayer \& Mische, 1998). As far as sustainability agency is concerned, a systemic perspective covering all three temporal dimensions is welcome. What is more, there appears to be a dearth of empirical research on agency, as contrasted with the abstract theorizing work involved. Academics have been invited to empirically study instances where agency occurs (Stones, 2005). Finally, the question of how agency translates toward collective action, ultimately altering the course of civilizations is timely in the twenty-first century. Answering such questions requires a continuous and collaborative effort cutting across the natural and social sciences.

\section{OVERVIEW OF THE BOOK'S CHAPTERS}

In this handbook, we proceed to an overview of prior research, across disciplines, on sustainability agency. Based on the above reviews of the concepts of sustainability and agency, for the purposes of this handbook we define sustainability agency as the capacity to act toward sustainable futures.

As contributors were called to participate in the handbook, we sought authors across the broad spectrum of sustainability agency, across disciplines, studying sustainability agency at different levels of analysis (i.e. individual, organizational, national, global). Author teams were asked to provide literature review-based chapters on the particular element of sustainability agency that they have expertise in, followed by a future research agenda. For the purposes of the handbook, chapters have been divided into four broad themes representing the book's respective sections. These themes include individual-level agency, active agency, relational agency, and governance.

\section{Part I: Individual Agency}

Part I discusses sustainability agency at the individual level. Chapter 2, titled 'Theorising individual agency within sociotechnical sustainability transitions frames: a social psychological view', by Paul Upham, Paula Bögel, Rita G. Klapper, and Eva Kašperová provides a review of extant research of individual-level agency in the field of sociotechnical sustainability transitions. The chapter assesses how constructs from social psychology have been used in this literature, ending with a call for more research on individual-level sustainability agency. The authors argue that present research on agency in sociotechnical sustainability transitions has largely focused on collective forms of agency, while the scant research on individual-level agency is skewed toward a positivist ontology.

Following this theoretical perspective, subsequent chapters dive into the realm of individuals' roles in organizations. It is thus that in Chapter 3, titled 'Sustainability agency at the top of the organization: microfoundations research on corporate sustainability', by Ashley Salaiz, Shih-Chi (Sana) Chiu, and Judith L. Walls assesses the state of the art in the study of strategic leaders, i.e. top managers and board directors, vis-à-vis a firm's sustainability strategy and performance. The onus is on the drivers of corporate sustainability among top managers, alongside the moderators, mediators, and boundary conditions of this work. The authors observe a shift in the field from a prior focus on firms' rationales for pursuing sustainability 
strategies toward an interest in key individuals undertaking this work. Such an approach calls for a microfoundations perspective for corporate sustainability.

Chapter 4, titled 'Not dinosaurs but dynamos: the roles of middle managers in corporate social responsibility and sustainable development issues', by Gustavo Birollo, Susana Esper, and Linda Rouleau shifts the level of analysis toward middle managers in organizations. The term middle managers is used in the chapter to denote those middle-level managers in organizations that are in charge of implementing sustainability-related work, be they in specific functions or assigned a formal sustainability-related role such as CSR manager. The authors identify middle managers engaging in three types of sustainability-related roles: influencing, implementing, and connecting. Given nascent interest in the field, the chapter ends with a call for further research on middle managers, a hitherto neglected sustainability actor, caught amid the paradox of negotiating one's role upward and downward in the organization while engaging in lateral stakeholder engagement.

Chapter 5, titled 'Barriers to implementing sustainability experienced by middle managers in the Fast-moving Consumer Goods and Retail sector', by Andrew Mountfield, Kelly Hrajnoha, Leslie Koh, Lija Lascenko, Renata Puchala, and Cornelia Schalch explores the nature of the barriers to implementing sustainability experienced by middle managers. The chapter is an empirical study, in which the authors conducted interviews with middle managers from companies in the Fast-Moving Consumer Goods \& Retail sector across the world. Authors find three barriers affecting sustainability agency: leadership structures and behaviors, formal management processes, and the perceived sense of agency of middle managers across strategy implementation beyond sustainability. The authors conclude that this topic would deserve further attention in more depth, in other industries and geographies.

Chapter 6, titled 'Employee agency in the context of organisational sustainability', by Sally Russell, Fay Giæver, and Tiina Onkila argues that instead of a focus on organizations and their decision-makers, future research ought to adopt an employee focus. Where such research has hitherto been undertaken, the perspective has often provided employees with a passive role. Instead, the authors call for future research to study the active roles that employees adopt as sustainability change agents. The chapter reviews prior research as regards employee sustainability behavior, including its drivers, how such behavior contributes to an organization's sustainability performance, and how employees can act as change agents within their employing organizations.

Chapter 7, titled 'The role of ambivalence in sustainable consumption: literature review and research agenda', by Jenni Sipilä provides a systematic review of extant literature on consumers' ambivalent behavior as regards sustainable consumption. The review assesses the conceptual and theoretical basis as regards ambivalence in the context of sustainable consumption, discusses its origins, the types of ambivalence toward sustainable consumption, how consumers cope with ambivalence, and its consequences for sustainable consumer behavior. This leads the author to develop a tripartite research agenda to address the conceptual, contextual, and empirical research gaps in the prevailing literature.

Summing up, chapters in the first part all observe the relative lack of prior interest in the study of sustainability agency at the individual level, particularly as regards active agency that seeks change. Notwithstanding, all chapters call for more research on various forms of individual-level agency, be it as top managers, middle managers, employees or consumers. 


\section{Part II: Active Agency}

Part II shifts attention toward active forms of sustainability agency. Such agency can occur at the individual and/or collective levels. These chapters focus on forms of agency, where individuals and/or organizations intentionally pursue sustainability agency. Our review identified the following types of active sustainable actors.

Chapter 8, titled 'Roles and practices of institutional workers in climate change action: a review', by Jan Hermes and Mikołaj Pawlak provides a systematic review of prior research on institutional work and climate change. The findings discuss the nature of institutional work, its forms, dimensions and temporality, the divide between climate protagonists and antagonists, the motivations and resources for institutional work, as well as the effects of institutional work. The authors conclude that the sustainability agency of institutional climate workers appears to escape classical divides, be it as regards individual or organizational levels of analysis, given a focus on coalitions of actors whose agency is obtained by assembling other actors. In closing, the authors propose a new form of institutional climate work, termed 'reformulating institutions', referring to the maintenance of climate-protecting institutions while reformulating them.

Chapter 9, titled 'Sustainability activism: a review of the state of the art', by Marileena Mäkelä and Laura Olkkonen proceeds to a multidisciplinary review of prior research on sustainability activism. The analysis focuses on identifying different types of activism, be it as regards actors, targets, issues addressed, or the means applied. The authors observe activism in the twenty-first century to be a multifaceted phenomenon, where different types of actors seek to transform businesses from within or as outsiders. Going forward, new types of activism including CEO or employee activism are called for.

Chapter 10, titled 'Emotions in sustainability work: the case of ecopreneurs', by Fay Giæver and Sally Russell pursues a dyadic agenda. On the one hand, the chapter reviews prior research on sustainability work, observing in particular the emotions related to this role. On the other hand, the chapter focuses its attention on the case of ecopreneurs. The authors argue that ecopreneurs exemplify sustainability workers, navigating a shifting sea of emotions, while pursuing a business with an environmental purpose. The authors suggest ecopreneurship to be a form of sustainability agency and consider means of coping for such actors. Going forward, the authors call for more interest in the emotions of ecopreneurs as well as the lived experience of sustainability work.

Chapter 11, titled 'Social entrepreneurship as sustainability agency' by Hanna Lehtimäki, Subhanjan Sengupta, Ville-Veikko Piispanen, and Kaisa Henttonen review prior research on social entrepreneurship, observing in particular its hybrid nature. The authors suggest social entrepreneurship as a form of sustainability agency, given that social entrepreneurs act as change agents for a sustainable future. Going forward, the authors call for more research on the means by which sustainability transitions occur as a result of bottom-up grassroots action.

In Chapter 12, titled 'Agency of citizen collectives in sustainable transitions: the case of renewable energy cooperatives in Europe', Thomas Hoppe and Beau Warbroek shift the attention toward citizens and their collective agency in the form of energy cooperatives. Such cooperatives illustrate a form of grassroots movement. The chapter assesses the type of agency that energy cooperatives have in sustainability transitions, defining community energy and renewable energy cooperatives, as well as the complex actor domain, involving incumbent firms and tradition-leaning policy-makers, in which such cooperatives operate. The authors 
then discuss the means via which energy cooperatives use their agency, at different societal levels of reach, as well as the challenges such cooperatives encounter. The chapter ends with a future research agenda.

In Chapter 13, titled 'Social movement organizations' agency for sustainable organizing', Helen Etchanchu, Frank G.A. de Bakker and Giuseppe Delmestri present the strategies, forms of organizing, and outcomes of sustainability-oriented social movement organizations. The authors identify social movements' agency as consisting in mobilizing collective action to achieve sustainability goals. The example of Extinction Rebellion is used in illustration. Going forward, research on contemporary forms of social movement organizing via digital, social media, and transnational forms are called for, as well as reflecting on the role of academia and academics as sustainability change agents.

Summing up, chapters in the second part highlight different types of active agency, be it at individual or collective levels. Authors converge on the idea that sustainability work involves a myriad of emotions, and thus emotional means of coping are required. Also, a number of paradoxes in sustainability work are raised. More research on sustainability antagonists is called for.

\section{Part III: Relational Agency}

Part III shifts attention toward relational forms of sustainability agency. Such agency connects individuals with organizations, organizations with each other, or individuals and organizations with materials. Our review identified the following types of relational sustainability agency.

In Chapter 14, titled 'Stakeholder engagement in sustainability transitions', Lara Gonzalez-Porras, Anna Heikkinen, Johanna Kujala, and Riikka Tapaninaho review the scholarly literature on stakeholders in the context of sustainability transitions. The authors identify stakeholder engagement occurring at the levels of the individual, the firm, the industry, and society. Stakeholder engagement is defined as a relational, multi-level process undertaken amid continuous stakeholder collaboration. Based on the review, the authors argued that, in addition to considering stakeholders as sustainability change agents, one can further consider the relational process of stakeholder engagement as a form of sustainability change agency.

Chapter 15, titled 'Partnerships to save the planet? Motivations, types and impacts of sustainability partnerships', Barbara Gray and Art Dewulf shift attention toward the multi-stakeholder partnerships involved in responding to sustainability challenges. The systematic literature review identifies the reasons for using partnerships in answering sustainability challenges, the myriad of forms of partnerships, the motives of different partners, be they governments, non-governmental organizations (NGOs), communities, or businesses, the obstacles to partnership success, and the outcomes of sustainability partnerships. The authors posit the importance of trust and collaboration toward partnership success, acknowledging the ongoing trade-offs that divide partner interests. Going forward, the authors call for increased attention on the 'how' of partnering, including questions on process, trust, accountability and participation.

Chapter 16, titled 'The role of sustainability agency in mergers and acquisitions', by Noelia-Sarah Reynolds and Melanie E. Hassett dives into the particular example of mergers and acquisitions (M\&As) as a specific form of partnering involving change of ownership. While CSR literature has assumed that firms grow organically, this chapter focuses on what happens when firms grow via the purchase of other firms or organizations. Based on a review 
of the literature, the authors observe an overall paucity of research interest toward sustainability perspectives in the study of M\&As, though noting a recent uptake in interest as regards drivers and process. The performance of M\&As remains measured using financial metrics only, thus disregarding elements of social or environmental sustainability. Going forward, the authors call for a research agenda that accounts for sustainability in the study and practice of M\&As.

Chapter 17, titled 'Circular economy ecosystems: a typology, definitions, and implications', by Leena Aarikka-Stenroos, Paavo Ritala and Llewellyn D.W. Thomas focuses on the phenomenon of circular economy. While ecosystems have been studied in several management sub-disciplines, this chapter identifies three categories of circular economy ecosystems. The authors discuss their definitions, composition, agency dynamics, and outcomes, proposing a framework of ecosystem types to guide further research. Future research is needed to inquire into the interplay of individual vs. organizational agency in circular economy ecosystems, as well as appreciate how such ecosystems evolve.

Chapter 18, titled 'Agency and sustainability in the construction industry', by Niamh Murtagh and Natalya Sergeeva provides a review of prior research on sustainability agency in the context of the built environment, a major source of negative environmental impact. Following a review of theories of agency, the authors identify sustainability agency in construction at the level of individuals, projects, and organizations. It is further observed that sustainability agency in the construction sector can occur in networks of individuals, projects and/or organizations as well as in materials, such as buildings or raw materials. Going forward, the authors offer a rich and diverse agenda for future research.

Chapter 19, titled 'Distributed agency in living labs for sustainability transitions', by Anil Engez, Paul H. Driessen, Leena Aarikka-Stenroos, and Marika Kokko argues for a decentralized, distributed form of agency, where actors work toward a common goal. The chapter builds on a single case study of public-private urban development in Finland, focusing on distributed agency in living laboratory settings. Such living labs are spaces of innovation that provide the opportunity of scaling up new ideas.

Chapter 20, titled 'The interagency cycle in sustainability transitions', by Ari Jokinen, Jarmo Uusikartano, Pekka Jokinen, and Marika Kokko brings forward the importance of non-human agency via the notion of material agency. Beyond a review of relevant theory on non-material agency, the authors provide an illustrative case study, based on which they develop the notion of inter-agency as occurring in the interaction between individuals and materials. Such inter-agency is particularly relevant, for example, in the context of the circular economy. The chapter defines the inter-agency cycle as the interplay between individuals and material, over iterative cycles of development. This provides a perspective toward divergent potential sustainability transition pathways depending on the path adopted in such developmental cycles.

Summing up, the third part highlights how sustainability agency is manifested and occurs in relationships and collaboration with others. Thus, it is not a form of agency that can be reduced to the level of an individual or organizational actor only. The relational nature of sustainability agency appears central to appreciating what sustainability agency is. Going forward, more research on these many ways of collaborating, be it via projects, partnerships, networks, ecosystems, mergers, distributed agency, living laboratories, or with materials, is needed. 


\section{Part IV: Governance}

Part IV focuses on governance as a form of sustainability agency. Such agency has been largely studied via the role of major governing organizations, such as governments or cities, as well as governing institutions, such as law. While the bulk of research focuses on developed countries and via the example of India, we provide an example of social sustainability in a developing economy. Beyond such formal forms of governance, the section then brings forth the role of non-governance via the example of informal economies and the actors therein.

Chapter 21, titled 'Law, agency and sustainability: the role of law in creating sustainability agency' by Jaakko Salminen and Mikko Rajavuori provides a critical review of law as a form of sustainability agency. While the role of law in calibrating sustainability agency ex post, via regulatory interventions, has been the object of prior legal research, there has been a paucity of interest in the role of private law. Building on a historical overview from the rise of the industrial organization to contemporary global multinationals and supply chains, toward platform economies, the authors find private law mechanisms, in their present form, to be perpetrators of unsustainable agency in private contracts, by commercial firms, property, multinational firms, supply chains, and platform economies. Going forward, they call for more research and action to bridge these gaps in order for legal frameworks, both public and private, to enable and enhance sustainability agency. In particular, there are opportunities for cross-disciplinary research between various social and management disciplines and law.

Chapter 22, titled 'Predictions from Transition theories, Dynamic Capabilities and Real Options theory on the role of governments as agents of sustainability', by Ilias Krystallis and Katariina Koistinen offers three novel theoretical perspectives to the study of governments as sustainability agents. The authors find these three theories to adopt different perspectives as to the role of markets vs. governments and with respect to the role of governments as change agents. However, they all posit that successful policy agency requires various forms of collaboration, be it via policy mixes, public-private partnerships, or the tensions between competition and collaboration. In closing, the authors observe the need to appreciate the dependencies between institutions and actor types, and the role of governments acting amid this web of actors. Going forward, the chapter is a call for more cross-fertilization between theoretical perspectives and disciplines in the study of sustainability transitions.

Chapter 23, titled 'Local governments using their agency in sustainability transitions' by Thomas Hoppe reviews prior research on the role of cities as sustainability agents, illustrating examples of cities' roles therein. The chapter draws attention to the multiplicity of actors with which local governments need to negotiate in the realm of sustainable development, as well as to the challenges this sector faces vis-à-vis sustainability. The study of cities is scattered amid three disciplines, each with its different foci. Going forward, more research in particular on circularity in cities is called for.

Chapter 24, titled 'Corporate sustainability from a strategic management perspective: one way for companies to support sustainability transitions', by Romana Rauter and Sabrina Lämmerer offers a critical review of prior research on companies' sustainability strategies as well as an agenda for future research. The authors review prior research on firms' motivations to pursue sustainability strategies as well as the means of implementing such strategies. While much has been researched on the motivations for companies' sustainability strategies, there is less knowledge on the actual implementation of such strategies. The authors call for more 
research on 'how' questions, as well as sustainability strategies of firms in specific sectors, across sectors, and comparative studies of firms at different stages of sustainability transitions.

Chapter 25, titled 'Sustainable consumption in the developing world: the case of India', by Shenaz Rangwala and Chanaka Jayawardhena calls for more research on sustainable consumption in the developing world, where top-down government-led efforts toward sustainable development are less marked than in the developed world. In their review, they focus on the social dimensions of sustainable consumption in the case of India, identifying the role of societal structures, traditions, and indigenous methods of consumption, as well as voluntary and social acts in promoting sustainable consumption. Given that sustainable consumption occurs at multiple levels, from the individual and household to the community, region, and country levels, the authors call for future research on these different levels of consumption and their connectedness. Policy recommendations for government are also provided as well as a call for more education on sustainable consumption.

Chapter 26, titled 'Sustainability practices in informal economies: actors, roles and research outlook', by Stefan Gröschl offers an overview of informal economies from a sustainability perspective. Despite their economic and social importance, in particular in the developing world, prior research has largely neglected such non-formal economic activity, also as regards their sustainability in-prints. The author offers a rich agenda for future research in order to appreciate the many actors involved in informal economies, and the roles and practices they adopt toward sustainable development. Recommendations for governments, economists and gender researchers are also provided.

\section{Part V: Sustainability Agency}

With a view to closing, Chapter 27, titled 'Synthesis and future research directions', by the handbook editors Satu Teerikangas, Katariina Koistinen, Tiina Onkila and Marileena Mäkelä offers a meta-review of the entire handbook as regards how the terms sustainability, agency, and sustainability agency are approached by the chapters. The editors then provide a synthesis of what sustainability agency is, and what are its defining characteristics and paradoxes. The chapter closes with a summative overview of research directions emerging from the chapters, as well as from the handbook as a whole. The handbook is a call for sustainability agency.

\section{ACKNOWLEDGEMENTS}

The authors are appreciative to the From Innovation to Business Ecosystems (CICAT2025) project (0245896-2018) of the Strategic Research Council of the Academy of Finland, which has supported the work reported here.

\section{REFERENCES}

Ackroyd, P. (2009), Venice, the Pure City, London: Vintage Publishing.

Aguinis, H. (2011), 'Organizational responsibility: Doing good and doing well', in S. Zedeck (ed.), APA Handbook of Industrial and Organizational Psychology, Washington, DC: American Psychological Association, pp. 855-879. 
Aldous, D. (2014), 'Understanding the complexity of the lived experiences of Foundation Degree sport lecturers within the context of Further Education', Sport, Education and Society, 19 (4), 472-488.

Archer, M. S. (1982), 'Morphogenesis versus structuration: On combining structure and action', British Journal of Sociology, 33, 455-483.

Archer, M. S. (1988), Culture and Agency: The Place of Culture in Social Theory, Cambridge: Cambridge University Press.

Avelino, F. (2017), 'Power in sustainability transitions: Analysing power and (dis)empowerment in transformative change towards sustainability', Environmental Policy Governance, 27, 505-520.

Avelino, F., \& Wittmayer, J. M. (2016), 'Shifting power relations in sustainability transitions: A multi-actor perspective', Journal of Environmental Policy and Planning, 18, 628-649.

Aylett, A. (2015), 'Relational agency and the local governance of climate change: International trends and an American exemplar', in C. Johnson, N. Toly, \& H. Schroeder (eds.), The Urban Climate Challenge, Rethinking the Role of Cities in the Global Climate Regime, London: Routledge, pp. 156-179.

Baber, Z. (1991), 'Beyond the structure/agency dualism: An evaluation of Giddens' theory of structuration', Sociological Inquiry, 61, 219-230.

Bakewell, R. (1815), An Introduction to Geology, Illustrative of the General Structure of the Earth, London: J. Harding Publishing.

Bandura, A. (1997), Self-efficacy: The Exercise of Control, New York: Freeman.

Bandura, A. (2001), 'Social cognitive theory: An agentic perspective', Annual Review of Psychology, 52, 1-26.

Bandura, A. (2006), 'Toward a psychology of human agency', Perspectives on Psychological Science, $1(2), 164-180$.

Bernstein, R. J. (1989), 'Social theory as critique', in D. Held \& J. B. Thompson (eds.), Social Theory of Modern Societies: Anthony Giddens and His Critics, Cambridge: Cambridge University Press, pp. 19-33.

Bice, S. (2017), 'Corporate social responsibility as institution: A social mechanisms framework', Journal of Business Ethics, 143, 17-34.

Biographia Britannica (1766), ed. W. Oldys, W. Innys Publisher.

Birkeland, I. (2008), 'Cultural sustainability: Industrialism, placelessness and the re-animation of place', Ethics, Place and Environment, 11 (3), 283-297.

Bögel, P. M., \& Upham, P. (2018), 'The role of psychology in sociotechnical transitions literature: A review and discussion in relation to consumption and technology acceptance', Environmental Innovation and Societal Transitions, 28, 122-136.

Brand, F. (2009), 'Critical natural capital revisited: Ecological resilience and sustainable development', Ecological Economics, 68 (3), 605-612.

Brundtland, G. H. (1987), Our Common Future: Report of the World Commission on Environment and Development, New York: United Nations Commission.

Burkitt, I. (2015), 'Relational agency: Relational sociology, agency and interaction', European Journal of Social Theory, 19 (3), 322-339.

Burns, T. R., \& Flam, H. (1986), The Shaping of Social Organizations: Social Rule System Theory with Applications, Beverly Hills, CA: Sage.

Caldwell, R. (2005), 'Things fall apart? Discourses and agency and change in organizations', Human Relations, 58 (1), 83-114.

Carson, R. ([1962] 2009), Silent spring. 1962. Boston, MA: Houghton Mifflin.

Chappin, E. J. L., \& Ligtvoet, A. (2014), 'Transition and transformation: A bibliometric analysis of two scientific networks researching socio-technical change', Renewable and Sustainable Energy Reviews, 30, 715-723.

Christen, M., \& Schmidt, S. (2012), 'A formal framework for conceptions of sustainability - a theoretical contribution to the discourse in sustainable development', Sustainable Development, 20, 400-410.

Clayton, S., Devine-Wright, P., Stern, P., Whitmarsh, L., Carrico, A., Steg, L., ... Bonnes, M. (2015), 'Psychological research and global climate change', Nature Climate Change, 5, 640-646.

Coad, A., Jack, L., \& Kholeif, A. O. R. (2015), 'Structuration theory: Reflections on its further potential for management accounting research', Qualitative Research in Accounting \& Management, 12 (2), 153-171. 
Cochran, L., \& Laub, J. (1993), Becoming an Agent: Patterns and Dynamics for Shaping Your Life, Albany, NY: SUNY Press.

Craib, J. (1992), Anthony Giddens, London: Routledge.

Crilly, D., Schneider, S., \& Zollo, M. (2008), 'Psychological antecedents to socially responsible behavior', European Management Review, 5 (3), 175-190.

Crozier, M., \& Friedberg, E. (1980), Actors and Systems: The Politics of Collective Action, Chicago: University of Chicago Press.

Dahlsrud, A. (2008), 'How corporate social responsibility is defined: An analysis of 37 definitions', Corporate Social Responsibility and Environmental Management, 15 (1), 1-13.

Darwin, C. (1859), On the Origin of Species by Means of Natural Selection, London: John Murray.

Dawe, A. (1978), 'Theories of social action', in T. Bottomore \& R. Nisbet (eds.), A History of Sociological Analysis, New York: Basic Books, pp. 362-417.

de Bakker, F., den Hond, F., King, B., \& Weber, K. (2013), 'Social movements, civil society and corporations: Taking stock and looking ahead', Organization Studies, 34 (5-6), 573-593.

De Groot, R., Van der Perk, J., Chiesura, A., \& Van Vliet, A. (2003), 'Importance and threat as determining factors for criticality of natural capital', Ecological Economics, 44 (2-3), 187-204.

de Haan, F. J., \& Rotmans, J. (2018), 'A proposed theoretical framework for actors in transformative change', Technological Forecasting and Social Change, 128, 275-286.

Dietz, T., \& Burns, T. R. (1992), 'Human agency and the evolutionary dynamics of culture', Acta Sociologica, 35, 187-200.

Doh, J., Lawton, T., \& Rajwani, T. (2012), 'Advancing nonmarket strategy research: Institutional perspectives in a changing world', Academy of Management Perspectives, 26, 22-39.

Dyllick, T., \& Muff, K. (2015), 'Clarifying the meaning of sustainable business: Introducing a typology from business-as-usual to true business sustainability', Organization \& Environment, 29 (2), 156-174.

Eisenhardt, K. (1989), ‘Agency theory: An assessment and review', Academy of Management Review, $14(1), 57-74$.

Elkington, J. (1999), Cannibals with Forks: The Triple Bottom Line of 21st Century Business, Oxford: Capstone Publishing Limited.

Emirbayer, M., \& Mische, A. (1998), 'What is agency?', American Journal of Sociology, 103 (4), 962-1023.

FAO (Food and Agriculture Organization of the United Nations). (2017), The Future of Food and Agriculture: Trends and Challenges, Rome, Italy: FAO.

Farla, J., Markard, J., Raven, R., \& Coenen, L. (2012), 'Sustainability transitions in the making: A closer look at actors, strategies and resources', Technological Forecasting Social Change, 79 (6), 991-998.

Fischer, L. B., \& Newig, J. (2016), 'Importance of actors and agency in sustainability transitions: A systematic exploration of the literature', Sustainability, 8 (5), 476.

Fjellstedt, L. (2015), Examining Multidimensional Resistance to Company Change: A Strong Structuration Approach, Washington, DC: The George Washington University, Anne Arbor, MI: ProQuest LLC.

Folke, C., Jansson, Å., Rockström, J., Olsson, P., Carpenter, S., Chapin III, F., et al. (2011), 'Reconnecting to the biosphere', Ambio, 31 (5), 437-440.

Garud, R., \& Gehman, J. (2012), 'Metatheoretical perspectives on sustainability journeys: Evolutionary, relational and durational', Research Policy, 41, 980-995.

Garud, R., \& Karnøe, P. (2001), 'Path Creation as a Process of Mindful Deviation', in R. Garud and P. Karnøe (eds.), Path Dependence and Creation, Lawrence Erlbaum Associates, pp. 1-40.

Geels, F. W. (2002), 'Technological transitions as evolutionary reconfiguration processes: A multi-level perspective and a case-study', Research Policy, 31, 1257-1274.

Geels, F. (2011), 'The multi-level perspective on sustainability transitions: Responses to seven criticisms', Environmental Innovation and Societal Transitions, 1, 24-40.

Geels, F. W., \& Schot, J. (2007), 'Typology of sociotechnical transition pathways', Research Policy, 36 (3), 399-417.

Ghoshal, S. (2005), 'Bad management theories are destroying good management practice', Academy of Management Learning and Education, 4 (1), 75-91.

Giddens, A. (ed.) (1984), The Constitution of Society: Outline of the Theory of Structuration, Berkeley, CA: University of California Press. 
Giddens, A. (1989), 'A reply to my critics', in D. Held and J. B. Thompson (eds.), Social Theory of Modern Societies: Anthony Giddens and His Critics, Cambridge: Cambridge University Press, pp. 249-301.

Giddens, A., \& Sutton, P. W. (2017), Essential Concepts in Sociology, 2nd edition, Cambridge, UK: Polity Press.

Giovannoni, E., \& Fabietti, G. (2013), 'What is sustainability? A review of the concept and its applications', in C. Busco, M. Frigo, A. Riccaboni, \& P. Quattrone (eds.), Integrated Reporting, Cham: Springer, pp. 21-40.

Goranova, M., \& Ryan, L. (2014), 'Shareholder activism: A multidisciplinary review', Journal of Management, 40 (5), 1230-1268.

Gousse-Lessard, A-S., Vallerand, R., Carbonneau, N., \& Lafreniere, M., (2013), 'The role of passion in mainstream and radical behaviors: A look at environmental activism', Journal of Environmental Psychology, 35, 18-29.

Griggs, D., Stafford-Smith, M., Gaffney, O., Rockström, J., Öhman, M. C., Shyamsundar, P. ... Noble, I. (2013), 'Sustainable development goals for people and planet', Nature, 495 (7441), 305-307.

Haugh, H. M., \& Talwar, A. (2010), 'How do corporations embed sustainability across the organization?', Academy of Management Learning \& Education, 9 (3), 384-396.

Heaney, M., \& Rojas, F. (2014), 'Hybrid activism: Social movement mobilization in a multimovement environment', American Journal of Sociology, 119 (4), 1047-1103.

Hediger, W. (1999), 'Reconciling "weak" and "strong”, sustainability', International Journal of Social Economics, 26 (7/8/9), 1120-1143.

Holden, G. (1991), 'The relationship of self-efficacy appraisals to subsequent health-related outcomes: A meta-analysis', Social Work in Health Care, 16, 53-93.

Holden, G., Moncher, M. S., Schinke, S. P., \& Barker, K. M. (1990), 'Self-efficacy of children and adolescents: A meta-analysis', Psychological Reports, 66, 1044-1046.

IEA (International Energy Agency) (2018), Key World Energy Statistics, Paris: IEA.

IPCC (Intergovernmental Panel on Climate Change) (2014), AR5 Synthesis Report: Climate Change 2014, accessed 31 March 2021 at https://www.ipcc.ch/report/ar5/syr/.

IWMI (International Water Management Institute). (2018), IWMI Annual Report 2018, Colombo, Sri Lanka: IWMI.

Jensen, M., \& Meckling, W. (1976), 'Theory of the firm: Managerial behavior, agency costs and ownership structure', Journal of Financial Economics, 3, 305-360.

Kim, A., Kim, Y., Han, K., Jackson, S. E., \& Ployhart, R. E. (2017), 'Multilevel influences on voluntary workplace green behavior: Individual differences, leader behavior, and coworker advocacy', Journal of Management, 43 (5), 1335-1358.

Knappett, C., \& Malafouris, L. (2008), 'Material and nonhuman agency: An introduction', in C. Knappett \& L. Malafouris (eds.), Material Agency, Boston, MA: Springer, pp. ix-xix.

Knippenberg, L., \& de Jong, E. B. P. (2010), 'Moralising the market by moralising the firm: Towards a firm-oriented perspective of corporate social responsibility', Journal of Business Ethics, 96 (1), $17-31$.

Koistinen, K., Teerikangas, S., Mikkilä, M., \& Linnanen, L. (2018), 'Agent-based change in facilitating sustainability transitions', in S. Dhiman \& J. Marques (eds.), Handbook of Engaged Sustainability. Cham: Springer, pp. 1-23.

Koistinen, K., Teerikangas, S., Mikkilä, M., \& Linnanen, L. (2020), 'Active sustainability actors: A life course approach', Sustainable Development, 28, 208-223.

Kuhlman, T., \& Farrington, J. (2010), 'What is sustainability?', Sustainability, 2 (11), 3436-3448.

Köhler, J., Geels, F. W., Kern, F., Markard, J., Wieczorek, A., Alkemade, F., ... Wells, P. (2019), 'An agenda for sustainability transitions research: State of the art and future directions', Environmental Innovation and Societal Transitions, 31, 1-32.

Lambell, R., Ramia, G., Nyland, C., \& Michelotti, M. (2008), 'NGOs and IB research: Progress, prospects and problems', International Journal of Management Reviews, 10 (1), 75-92.

Lamont, M., \& Wuthnow, R. (1990), 'Betwixt and between: Recent cultural sociology in Europe and the United States', in G. Ritzer (ed.), Frontiers of Social Theory: The New Syntheses, New York: Columbia University Press, pp. 287-315. 
Latour, B. (1987), Science in Action: How to Follow Scientists and Engineers Through Society, Milton Keynes: Open University Press.

Latour, B. (1996), 'On actor-network theory: A few clarifications', Soziale Welt, 47, 369-381.

Latour, B. (2005), Reassembling the Social: An Introduction to Actor-Network-Theory, Oxford: Oxford University Press.

Law, J. (1992), 'Notes on the theory of the actor-network: Ordering, strategy and heterogeneity', Systems Practice, 5, 379-393.

Law, J. (2008), 'Actor-network theory and material semiotics', in B. S. Turner (ed.), The New Blackwell Companion to Social Theory, 3rd edition, Oxford: Blackwell, pp. 141-158.

Lawrence, T., Suddaby, R., \& Leca, B. (2009), 'Introduction: Theorizing and studying institutional work', in T. B. Lawrence, R. Suddaby, \& B. Leca (eds.), Institutional Work: Actors and Agency in Institutional Studies of Organizations, Cambridge: Cambridge University Press, pp. 1-28.

Loorbach, D., Frantzeskaki, N., \& Avelino, F. (2017), 'Sustainability transitions research: Transforming science and practice for societal change', Annual Review of Environment and Resources, 42, 599-626.

Málovics, G., Csigéné, N. N., \& Kraus, S. (2008), 'The role of corporate social responsibility in strong sustainability', The Journal of Socio-Economics, 37 (3), 907-918.

Markard, J., Raven, R., \& Truffer, B. (2012), 'Sustainability transitions: An emerging field of research and its prospects', Research Policy, 41, 955-967.

Markman, G., \& Waldron, T. (2014), 'Small entrants and large incumbents. A framework for micro entry', The Academy of Management Perspectives, 28 (2), 179-197.

Meadows, D. H., Meadows, D. L., Randers, J., \& Behrems, W. (1972), The Limits to Growth, New York: Universe Books.

Merton, R. K. (1949), Social Theory and Social Structure, New York: Free Press.

Mill, J. S. ([1848] 1999), Principles of Political Economy, Oxford: Oxford University Press.

Mintzberg, H. (1994), The Rise and Fall of Strategic Planning, London: Prentice Hall.

Nilsson, M., Griggs, D., \& Visbeck, M. (2016), 'Policy: Map the interactions between Sustainable Development Goals', Nature, 534 (7607), 320-322.

Onkila, T., \& Sarna, B. (2017), 'Employees as a stakeholder for CSR - a literature review', paper presented at the Corporate Responsibility Research Conference, Seville, Spain.

Onkila, T., Teerikangas, S., Mäkelä, M., \& Koistinen, K. (2019), 'Sustainability agency: Actors attributes and strategies - a systematic review of CSR literature', paper presented at the Corporate Responsibility Research Conference, Tampere, Finland.

OED (n.d.), Oxford English Dictionary, accessed 16 September 2020 at https://www.oed.com/.

Pacheco, D., York, J., Dean, T., \& Sarasvathy, S. (2010), 'The coevolution of institutional entrepreneurship: A tale of two theories', Journal of Management, 36 (4), 974-1010.

Pelenc, J., \& Dedeurwaerdere, T. (2015), Weak Sustainability versus Strong Sustainability. Brief for the Global Sustainable Development Report, accessed 20 October 2016 at https://sustainabledevelopment .un.org/content/documents/6569122-Pelenc-Weak\%20Sustainability\%20versus\%20Strong $\% 20$ Sustainability.pdf.

Pesch, U. (2015), 'Tracing discursive space: Agency and change in sustainability transitions', Technological Forecasting and Social Change, 90, 379-388.

Pettigrew, A. M. (1997), 'What is processual analysis', Scandinavian Journal of Management, 13, 337-348.

Quinn, J. B. (1980), Strategies for Change: Logical Incrementalism, Homewood, IL: Irwin.

Raineri, N., \& Paillé, P. (2016), 'Linking corporate policy and supervisory support with environmental citizenship behaviors: The role of employee environmental beliefs and commitment', Journal of Business Ethics, 137 (1), 129-148.

Ritzer, G. (2000), Sociological Theory, 5th edition, Singapore: McGraw-Hill.

Rockström, J., Steffen, W., Noone, K., Persson, A., Chapin, F. S., Lambin, E. F., ... Foley, J. F. (2009), 'A safe operating space for humanity', Nature, 461 (7263), 472-475.

Rodell, J., Breitsohl, H., Schröder, M., \& Keating, D. (2016), 'Employee volunteering: A review and framework for future research. Journal of Management, 42 (1), 55-84.

Sarkar, S., \& Searcy, C. (2016), 'Zeitgeist or chameleon? A quantitative analysis of CSR definitions', Journal of Cleaner Production, 135, 1423-1435. 
Schwandt, D. R., \& Szabla, D. B. (2013) 'Structuration theories and complex adaptive social systems: Inroads to describing human interaction dynamics', Emergence: Complexity and Organization, (4), 1-20.

Scientific American Monthly (1921), Jan. 76 (1), accessed 6 April 2021 at https://www.scientificamerican $. \mathrm{com} /$.

Seefried, E. (2015), 'Rethinking progress. On the origin of the modern sustainability discourse, 1970-2000', Journal of Modern European History, 13 (3), 377-400.

Senge, P. (1990), The Fifth Discipline, London: Random House.

Seo, M., \& Creed, W. (2002), 'Institutional contradictions, praxis, and institutional change: A dialectical perspective', Academy of Management Review, 27 (2), 222-247.

Simon, H. (1947), Administrative Behaviour, New York: Macmillan.

Soini, K., \& Birkeland, I. (2014), 'Exploring the scientific discourse on cultural sustainability', Geoforum, 51, 213-223.

Steffen, W., Richardson, K., Rockström, J., Cornell, S., Fetzer, I., Bennett, E., ... Sörlin, S. (2015), 'Planetary boundaries: Guiding human development on a changing planet', Science, 347 (6223). DOI: $10.1126 /$ science. 1259855.

Stones, R. (2005), Structuration Theory, Basingstoke: Palgrave Macmillan.

Teerikangas, S., Onkila, T., Niemi, L., Koistinen, K., \& Mäkelä, M. (2018), 'Agency in sustainability transitions - a 25-year review of research in management journals', paper presented at the 13th Corporate Responsibility Research Conference, 11-12 September, Leeds, UK.

Touraine, A. (1977), The Self-production of Society, Chicago: University of Chicago Press.

United Nations (2019), Global Sustainable Development Report, accessed 31 March 2021 at https://su stainabledevelopment.un.org/globalsdreport/.

United Nations. (2020), Sustainable Development Goals, accessed 6 October 2020 at https://www.un .org/sustainabledevelopment/sustainable-development-goals/.

Upham, P., Dütschke, E., Schneider, U., Oltrad, C., Sala, R., Lores, M., Klapper, R., \& Bögel, P. (2018), 'Agency and structure in a sociotechnical transition: Hydrogen fuel cells, conjunctural knowledge and structuration in Europe', Energy Research and Social Science, 188, 163-174.

Wassmer, U., Paquin, R., \& Sharma, S. (2014), 'The engagement of firms in environmental collaborations: Existing contributions and future directions', Business \& Society, 53 (6), 754-786.

Williams, C., \& Millington, A. (2004), 'The diverse and contested meanings of sustainable development', The Geographical Journal, 170 (2), 99-104.

Wilson, R. (1968), 'On the theory of syndicates', Econometrica, 36, 119-132.

WWF (2020), Living Planet Report 2020, accessed 31 March 2021 at https://livingplanet.panda.org/. 